\title{
«Cahiers Claude Simon», 5, sous la direction de Jean-Yves Laurichesse
}

\section{Massimiliano Catoni}

\section{Q OpenEdition \\ 1 Journals}

\section{Edizione digitale}

URL: http://journals.openedition.org/studifrancesi/6437

DOI: 10.4000/studifrancesi.6437

ISSN: 2421-5856

\section{Editore}

Rosenberg \& Sellier

\section{Edizione cartacea}

Data di pubblicazione: 1 novembre 2010

Paginazione: 591

ISSN: 0039-2944

\section{Notizia bibliografica digitale}

Massimiliano Catoni, ««Cahiers Claude Simon», 5, sous la direction de Jean-Yves Laurichesse», Studi Francesi [Online], 162 (LIV | III) | 2010, online dal 30 novembre 2015, consultato il 14 janvier 2021. URL: http://journals.openedition.org/studifrancesi/6437 ; DOI: https://doi.org/10.4000/studifrancesi.6437

Questo documento è stato generato automaticamente il 14 janvier 2021.

\section{(c) (i) (9)}

Studi Francesi è distribuita con Licenza Creative Commons Attribuzione - Non commerciale - Non opere derivate 4.0 Internazionale. 


\title{
«Cahiers Claude Simon», 5, sous la direction de Jean-Yves Laurichesse
}

\author{
Massimiliano Catoni
}

\section{NOTIZIA}

«Cahiers Claude Simon», 5, sous la direction de Jean Yves LAURICHESSE, Perpignan, Presses Universitaires de Perpignan, 2009, pp. 170.

1 Per dar conto dell'ultimo numero della rivista, edita dalle Presses Universitaires de Perpignan, dell'Association de Lecteurs de Claude Simon è utile, forse, cominciare dalla fine, e cioè dall'intervento che chiude questa raccolta: Le Dernier Cavalier di Jean RouAuD. L'obiettivo di Rouaud, del resto, è chiaro: dissipare quei luoghi comuni che, a suo giudizio, incombono sulla figura di Simon. Vi è anzitutto un problema di prospettive: davvero Simon era interessato soltanto agli aspetti formali della letteratura? La risposta di Rouaud non lascia spazio a dubbi: i romanzi di Simon, ci dice, sono troppo ancorati alla Storia per potersi situare in qualche astratta regione formalista. «Comme si derrière la bataille de Pharsale ou de n'importe où se dissimulait la seule bataille recevable par les esprits du temps, la bataille de la phrase. Oublions que la guerre ne se paie pas de mots et que celui-là qui témoigne chevauchait sur la route des Flandres au milieu des cadavres des hommes [...] face à l'insoutenable, il était plus commode de faire de Claude Simon un forgeron de la langue» (p. 153).

2 Simon, d'altra parte, ha sempre sostenuto che solo la scrittura conta («après l'écriture il y a encore de l'écriture» p.147). Ha frustrato qualsiasi tentativo, da parte della critica, di muoversi sul terreno dei contenuti, provvedendo a edificare un muro dietro cui celare tutto quello che non fosse riferibile alla battaglia formalista in atto in quegli anni. Ed è proprio nel tentativo di aprire una breccia in quel muro che Rouaud avanza, infine, un'ipotesi suggestiva: lungi dall'essere semplicemente il testimone, insieme ad altri, della morte del romanzo, Simon è forse l'unico vero cantore della fine di un mondo: e più precisamente, della fine della Francia, o, meglio, «de sa fiction fondatrice, 
autant dire la fin du chevaleresque, la fin des romans de chevalerie, et par la même occasion la fin du roman, car c'est la même chose» (p. 151).

Resta da chiedersi cosa sopravviva di quel mondo accasciatosi su se stesso. E in che misura la scrittura saprà restituirlo all'autore.

4 Jean-Pierre DAUMARD nel suo intervento - La Mélancolie "Le Vent" - muove dall'esperienza della malinconia in Simon. L'accento è posto sul romanzo Le Vent. Ma la portata del discorso di Daumard è più ampia. Tocca il cuore stesso della poetica di Simon: «profusion baroque des plis de l'écriture, multiplication des perspectives sans espoir de perspective unique réalisant la présence» (p.65). Dunque la scrittura in Simon si configura come sforzo vano. Essa emana dalla consapevolezza che qualsiasi ipotesi di recupero dell'unità originaria (unità di un mondo che è andato perduto) è perfettamente illusoria. In tal senso, Aude MICHARD (Visage de l'idiotie dans "Le Vent" de Claude Simon), all'interno della sua minuziosa lettura de Le Vent, ci ricorda come, da un romanzo all'altro, l'alter ego simoniano (il Narratore) sia assalito da «une multitude de perceptions et de souvenirs simultanés» (p.43) che spesso non riesce a ordinare secondo un'architettura logica. Come se quel recupero di cui si parlava prima non potesse avvenire che per frammenti. Per istantanee.

5 Anche Annie CLÉMENT-PERRIER colloca il tema della malinconia al centro del suo intervento - La Photographie chez Claude Simon: un objet mélancolique? -, mettendo a fuoco, al contempo, il complesso rapporto tra fotografia e scrittura in Simon (caposaldo della critica simoniana). Il dato di partenza è questo: in ogni istantanea vi è necessariamente una componente di malinconia. Eppure le fotografie in Simon non si offrono come semplici reliquie da celebrare. Anziché produrre nel narratore un senso di prostrazione, esse generano una sorta di energia creatrice, la «nécessité vitale qui le pousse à arracher aux ténèbres du passé ce à quoi il veut avoir accès [...] de quoi nourrir un puissant désir de vivre» (p. 80). Ecco l'elemento di novità che Annie Clément-Perrier immette nel discorso: il desiderio. La malinconia in Simon è, appunto, «désirante» (p. 81) poiché rende esplicito e sommamente tangibile «le feu du désir d'écrire» (p. 82).

6 Questi sono solo alcuni dei temi sviluppati in questo numero dei «Cahiers Claude Simon». Occorre segnalare, in conclusione, che un'intera sezione di questo volume (Claude Simon et Barcelone. Derechef, a cura di Manuel A. TOST PLANET), dedicata al rapporto esclusivo che Simon intrattenne con la città di Barcellona, accoglie lettere e fotografie d'archivio. 